\title{
AVALIAÇÃO DE IMPLEMENTAÇÃO DO PROGRAMA NACIONAL DE TECNOLOGIA EDUCACIONAL: O CASO PROINFO NO MUNICÍPIO DE MOSSORÓ/RN
}

\author{
A. M. B. COSTA e L. C. B. GUERRA \\ Instituto Federal de Educação, Ciência e Tecnologia do Rio Grande do Norte \\ alane_mayara56@hotmail.com e lenin.cavalcanti@ifrn.edu.br \\ Artigo submetido em 25/07/2018 e aceito em 01/08/2018 \\ DOI: 10.15628/empirica.2018.7538s
}

\section{RESUMO}

Este trabalho objetivou avaliar o processo de implementação do Programa Nacional de Tecnologia Educacional - Proinfo, no município de Mossoró no Rio Grande do Norte

de modo a identificar os principais aspectos que tem facilitado ou obstaculizado o alcance da política pública. Para isso, foi utilizada uma proposta de Draibe (2001), qual sugere uma análise denominada anatomia do processo geral da implementação. Para alcançar os objetivos, foi realizado uma pesquisa de caráter qualitativo do tipo estudo de caso, utilizando-se de pesquisa documental e de entrevistas. Como resultados, é possível verificar a necessidade de novos investimentos para dar continuidade ao programa e mudanças em alguns setores para concretizar o objetivo do mesmo.

PALAVRAS-CHAVE: Política Pública, Prolnfo, Educação, Tecnologia, Município.

\section{EVALUATION OF IMPLEMENTATION OF THE NATIONAL PROGRAM OF EDUCATIONAL TECHNOLOGY: THE PROINFO CASE IN MOSSORÓ / RN}

\begin{abstract}
This work aimed to evaluate the process of implementation of the National Program of Educational Technology - Proinfo, in the municipality of Mossoró in Rio Grande do Norte. For this, a proposal of Draibe (2001) was used, which suggests an analysis called anatomy of the general process of the implementation. To reach the objectives, a qualitative research of the type of case study was carried out, using documentary research and interviews. As results, it is possible to verify the need for new investments to give continuity to the program and changes in some seotres to achieve the goal of the program.
\end{abstract}

KEYWORDS: Public Policy, Prolnfo, Education, Technology, Municipality. 


\section{INTRODUÇÃO}

O presente estudo tem como objetivo avaliar o processo de implementação do Programa Nacional de Tecnologia Educacional - Proinfo, no município de Mossoró no estado do Rio Grande do Norte. Este estudo situa-se no campo da avaliação de políticas públicas de educação contemporâneas, voltadas para a disseminação do uso pedagógico da informática nas escolas públicas de ensino. Para isso, foi utilizada uma proposta de Draibe (2001), a qual sugere uma análise denominada anatomia do processo geral da implementação. Para alcançar os objetivos, foi realizado uma pesquisa de caráter qualitativo do tipo estudo de caso, utilizando-se de pesquisa documental e de entrevistas.

As novas tecnologias vêm modificando significativamente as relações do homem com o mundo, visto que em cada segmento social encontramos a presença de instrumentos tecnológicos. A escola não pode ficar excluída desta realidade, devendo apropriar-se dos avanços tecnológicos e incorporá-los a prática educativa. Segundo Lévy (1996), a era atual das tecnologias da informação e comunicação estabelecem uma nova forma de pensar sobre o mundo que vem substituindo princípios, valores, processos, produtos e instrumentos que mediam a ação do homem com o meio.

0 acesso às tecnologias da informação e comunicação está relacionado com os direitos básicos de liberdade e de expressão, portanto os recursos tecnológicos são as ferramentas contributivas ao desenvolvimento social, econômico, cultural e intelectual. A inclusão tecnológica na escola oferece condições para a ampliação do conhecimento.

Sobre o uso das tecnologias como recurso pedagógico Demo (2009), enfatiza que através do computador as crianças aprendem muito mais do que ler e escrever, pois há materiais diversificados para ver, escutar, manipular e mexer. Assim, o professor precisa reinventar novas possibilidades em sala de aula, para que o aluno imagine, crie, se desenvolva e evolua no seu tempo dando mais significado a sua aprendizagem. Nesse sentido, percebe-se a importância de programas sociais como o Proinfo.

Nesse contexto, as políticas públicas no Brasil vêm gradativamente incorporando as Tecnologias de Informação e Comunicação - TICs, com o intuito de levar inclusão digital, tomando a educação como instrumento para isso. Prova disso, é o empenho de governos em implantar projetos desta natureza, como é o caso do Programa Nacional de Tecnologia Educacional - PROINFO, objeto de estudo desta pesquisa.

O PROINFO - Programa Nacional de Tecnologia Educacional é uma política pública de governo criada pelo Ministério da Educação e Cultura (MEC). De acordo com informações disponíveis no site oficial do MEC, o programa tem a finalidade de promover a melhoria do processo de ensino-aprendizagem através da introdução da informática na Rede Pública de Ensino Fundamental e Médio.

O programa leva ás escolas computadores, outros recursos digitais e conteúdos educacionais. Em contrapartida, estados, Distrito Federal e municípios devem garantir a estrutura adequada para receber os laboratórios e capacitar os educadores para uso das máquinas e tecnologias.

A presente pesquisa contribuirá para ampliar o conhecimento de avaliação de políticas públicas e adicionar novas perspectivas de análise para reflexão, uma vez que a avaliação de políticas públicas vem ganhando cada vez mais espaço nos estudos acadêmicos, embora os processos de formação da agenda e formulação de políticas ainda se sobressaiam (RAMOS E SCHABBACH, 2012) 


\section{ISSN - 2447-178X}

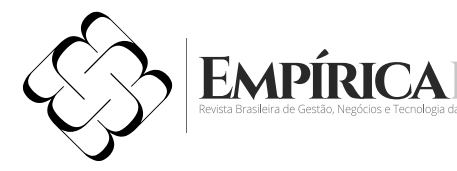

Ala-Harja e Helgason (2000) ressaltam que avaliações podem analisar organizações, funções, procedimentos, políticas, projetos etc. Neste sentido, este trabalho procura avaliar o processo de implementação da política de Educação a Distância por uma unidade credenciada para este fim. Para isso, buscou-se utilizar uma proposta de avaliação compatível com a referida política, chegando-se à desenvolvida por Sonia Draibe (2001), a qual sugere uma análise denominada anatomia do processo geral deimplementação. Tal análise é composta por seis subprocessos ou sistemas, quais sejam: sistema gerencial e decisório, processos de divulgação e informação, sistemas de seleção, sistemas de capacitação, sistemas internos de monitoramento e avaliação e sistemas logísticos e operacionais.

\section{REVISÃO BIBLIOGRÁFICA}

\subsection{Tecnologia na Educação}

A educação constitui a base de toda a formação e organização humana. Os instrumentos usados durante todo o processo é de extrema importância para construção e reprodução de visão de mundo, para formação de cidadãos. Um dos objetivos da educação é desenvolver a capacidade de tomar decisões conscientes, formar o cidadão para a sociedade, tornando-os mais crítico sobre assuntos do cotidiano. Contudo, é visível a necessidade de adequar o ensino/aprendizagem para que alcancem tais expectativas, criando assim, condições para que permitir conexões com o processo educacional e a evolução de recursos tecnológicos como meios para alcançar uma aprendizagem diferenciada e significativa.

$\mathrm{Na}$ atualidade a tecnologia da informação, vem crescendo cada vez mais, e no setor educacional não é diferente, visto que os recursos tecnológicos estão cada vez mais presentes na sala de aula e no contexto escolar. A história da humanidade é marcada por grandes avanços, e a valorização que a tecnologia da informação tem alcançado na atualidade, é desafiadora. (MORAN, 2000)

\footnotetext{
A tecnologia é um catalisador para a mudança nos processos de sala de aula, porque propicia um rumo diferente, uma mudança no contexto que sugere formas alternativas de operação. Ela pode impulsionar uma mudança de uma abordagem instrucional tradicional para um conjunto mais eclético de atividades de aprendizagem que inclui situações de construção de conhecimento para os alunos." (SANDHOLTZ, 1997, p.58)
}

O acesso às tecnologias da informação e comunicação está relacionado com os direitos básicos de liberdade e de expressão, portanto os recursos tecnológicos são as ferramentas contributivas ao desenvolvimento social, econômico, cultural e intelectual. A era da informática tem causado transformações importantes na educação, tendo em vista que as tecnologias da informação fornecem valiosos instrumentos de aprendizagem para o cotidiano escolar

Cresce a cada dia o uso da informática pelas escolas, tanto na área administrativa quanto na área pedagógica. Seu uso adequado contribui no desenvolvimento social, no convívio intercultural e na organização na construção do pensamento, bem como, desperta o interesse e a curiosidade dos 
alunos, elementos fundamentais para a construção do conhecimento. As inovações tecnológicas devem contribuir no processo educacional promovendo: a interatividade, a produção, a pesquisa, o debate, a sociabilidade, a democratização do conhecimento, a exploração de culturas, o acesso global do saber.

Moran (1995, p. 24-26) afirma:

\begin{abstract}
As tecnologias permitem um novo encantamento na escola, ao abrir suas paredes e possibilitar que alunos conversem e pesquisem com outros alunos da mesma cidade, país ou do exterior, no seu próprio ritmo. O mesmo acontece com os professores. Os trabalhos de pesquisa podem ser compartilhados por outros alunos e divulga dos instantaneamente na rede para quem quiser.
\end{abstract}

Segundo Fava (2014), A tecnologia está mudando a educação, não apenas na organização, escolha e disponibilidade dos conteúdos, mas também na distribuição. Isso obriga instituições de ensino a se adaptarem ou fracassarão nos novos conceitos da sociedade digital.

A escola como centro de formação e do saber não pode negar o relacionamento entre o conhecimento no campo da informática e os demais campos do saber humano. Trata-se de uma nova forma de linguagem e de comunicação, trata-se da linguagem digital. Sua história é como a história das demais formas de comunicação que surgiram anteriormente e para as quais os seres humanos mostraram resistência (GRINSPUN, 1999).

Incluir as tecnologias como apoio ao ensino aprendizagem é um grande desafio para a educação, principalmente na rede pública de ensino para dar igualdade de condições aos educandos. 0 educador necessita buscar ferramentas eletrônicas para atender a necessidade e a curiosidade dos educandos. São necessárias novas competências e atitudes para que o processo ensino-aprendizagem seja significativo.

A expressão "Tecnologia na Educação" abrange a informática, como também o uso da televisão, vídeo, rádio e até mesmo cinema na promoção da educação. Entende-se tecnologia como sendo o resultado da fusão entre ciência e técnica. 0 conceito de tecnologia educacional pode ser enunciado como o conjunto de procedimentos (técnicas) que visam "facilitar" os processos de ensino e aprendizagem com a utilização de meios (instrumentais, simbólicos ou organizadores) e suas consequentes transformações culturais. Um dos grandes desafios do mundo contemporâneo consiste em adaptar a educação à tecnologia moderna e aos atuais meios eletrônicos de comunicação.

(...) escolas que utilizam computadores no processo de ensino-aprendizagem apresentam melhorias nas condições de estruturação do pensamento do aluno com dificuldades de aprendizagem, compreensão e retenção. Colaboram, também, para melhor aprendizagem de conceitos matemáticos já que o computador pode constituirse um bom gerenciador de atividades intelectuais, desenvolverem a compreensão de conceitos matemáticos, promoverem o texto simbólico capaz de desenvolver 


\section{ISSN - 2447-178X}

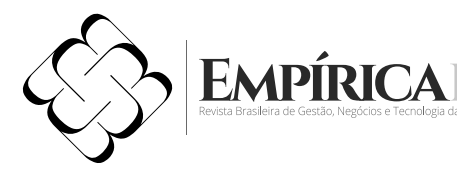

o raciocínio sobre ideias matemáticas abstratas, além de tornar a criança mais consciente dos componentes superiores do processo de escrita. (MORAES, 1998, p.13).

Pode-se observar que a informática é uma necessidade mundial, e que a escola tem a missão de preparar o aluno para essa realidade.

Nós, educadores, temos de nos preparar e preparar nossos alunos para enfrentar exigências desta nova tecnologia, e de todas que estão a sua volta - A TV, o vídeo, a telefonia celular. A informática aplicada à educação tem dimensões mais profundas que não aparecem a primeira vista. (ALMEIDA, 2000, p. 78)

Há vários recursos tecnológicos que podem facilitar o processo de aprendizagem. 0 computador, o principal produto das TICs, pois é rico em recursos audiovisuais possibilitando o entrecruzamento de imagens, sons, textos e diversos softwares educativos de apoio aos conteúdos curriculares que podem estimular os alunos para a aprendizagem.

Behar (2009) menciona a expectativa do poder público de que uso de ferramentas tecnológicas rompam com o gigantesco déficit educacional do nosso país, retratada a partir de investimentos maciços em projetos como PROINFO, Mídias na Educação e mais recentemente o UCA (Um Computador por Aluno). Apesar desses investimentos, ainda há poucos estudos que indiquem efetivamente como as tecnologias são incorporadas ao cotidiano escolar.

O governo criou o Programa Nacional de Tecnologia Educacional voltado para introdução das tecnologias nas escolas públicas do país, o chamado Proinfo. De acordo com a apresentação do programa disponível no item do Ministério da Educação e Cultura, o Proinfo é apresentado como:

[...] um programa educacional com o objetivo de promover o uso pedagógico da informática na rede pública de educação básica. 0 programa leva às escolas computadores, recursos digitais e conteúdos educacionais. Em contrapartida, estados, Distrito Federal e municípios devem garantir a estrutura adequada para receber os laboratórios e capacitar os educadores para uso das máquinas e tecnologias. (MEC, 2008)

O Programa Nacional de Tecnologia Educacional é um projeto do governo federal e tem como plataforma a integração da tecnologia à escola. Surgiu para atender a necessidade criada pela mudança e avanços tecnológicos do nosso tempo, mostrando que a incorporação das TIC ao ambiente de aprendizagem não é mais uma questão a ser debatida, mas um objetivo a ser alcançado.

O Prolnfo funciona através da parceria do Governo Federal com estados e municípios que, por sua vez, são responsáveis por alocar profissionais para trabalhar na capacitação dos cursos que devem ser ministrados aos professores nas escolas das escolas públicas nos chamados Núcleos de Tecnologia 
Educacional (NTE). Como cada instância é responsável pela aplicação do projeto individualmente, o programa acaba sendo desenvolvido de maneira fragmentada.

\subsection{Avaliação de Implementação de Políticas Públicas}

Segundo Rua (2009, p. 21) "as políticas públicas são resultante da atividade política". São, portanto, funções sociais possíveis de serem exercidas pelo Estado, tais como saúde, educação, previdência, moradia, saneamento básico, entre outras. Conforme Thoenig (2000) a avaliação é definida como um meio de aperfeiçoar a capacidade de aprender como conduzir mudanças bem-sucedidas e definir resultados alcançáveis nos campos da eficiência de pesquisa e eficácia públicas.

Portanto, a avaliação é uma ação que tem o objetivo de destacar o que se observa de uma política, programa ou projeto, se está sendo bem ou mal desenvolvido, se é correta ou não, e se necessita de modificações. Traz informações significativas para tomada de decisões, o que a deixa um papel importante.

A avaliação de políticas públicas relaciona-se à avaliação das políticas de determinados setores: educação, segurança, saúde, emprego, etc. Sobre os objetivos, métodos e técnicas, a avaliação de políticas públicas traz como perspectivas a eficácia, eficiência e efetividade. No caso da eficácia, considera-se a relação entre o previsto e o realizado; a eficiência, por seu turno, enfatiza como os recursos financeiros estão sendo utilizados; e a efetividade enfoca o que realmente foi modicado na vida dos beneficiários (THOENIG, 2000).

Segundo Stephanou (2005) a utilização de metodologias adequadas à avaliação de políticas públicas é uma preocupação constante de órgãos públicos, e também das agências de financiamento, pois muitos projetos apresentados não asseguram sequer a sustentação dos objetivos propostos na sua implementação. Para Cotta (1998) o conhecimento da metodologia de avaliação pode não substituir o conhecimento sobre as especificidades do programa, e que não existe uma única metodologia aplicável a todos os casos.

Dessa forma pode-se entender que a avaliação é um meio para conhecer o andamento de programas e projetos, entender suas propostas e atividades e se preciso reformula-las, nesse sentido, de acordo com a necessidade de quem a encomenda e dependendo do momento em que é realizada, a avaliação se mostra capaz, por exemplo, de determinar até que ponto os objetivos previamente estabelecidos foram alcançados, orientar ajustes no ciclo dos programas ou projetos, apontar razões para seu sucesso ou insucesso e investigar os efeitos inesperados sejam positivos ou negativos da intervenção.

Marjukka e Helgason ( 2000) reforçam que a avaliação de programas pode ser definida como uma análise sistemática de aspectos e importantes de um programa e seu valor, visando fornecer resultados confiáveis e utilizáveis, portanto, não visa conhecimento como um fim em si mesmo, mas como um meio para a ação".

Para Draibe (2001), a implementação de uma política inclui tanto as atividades-meio que viabilizam o desenvolvimento do programa, quanto a atividade-fim, ou a execução propriamente dita, antes que se torne rotineiro. E sua avaliação busca captar os fatores facilitadores e limitadores que circundam 
a implementação condicionando-a positiva ou negativamente no alcance de suas metas e objetivos. A autora ainda apresenta algumas contribuições como pontos fundamentais para uma avaliação de processo e implementação de uma política/programa, como mostra o quadro a seguir:

Quadro 1: Análise do Processo de Implementação.

\begin{tabular}{|l|l|}
\hline $\begin{array}{c}\text { Dimensão de Análise do Processo de } \\
\text { Implementação da Política Pública }\end{array}$ & \multicolumn{1}{|c|}{ Características-alvo da interlocução do Avaliador } \\
\hline $\begin{array}{l}\text { Subsistemagerencial e decisório } \\
\text { Processo de divulgação e informação }\end{array}$ & $\begin{array}{l}\text { Observar a estrutura organizacional e o sistema gerencial e decisório que } \\
\text { conduz a implementação - estrutura hierárquica do sistema, graus de } \\
\text { centralização e descentralização. }\end{array}$ \\
\hline Processo de seleção & $\begin{array}{l}\text { Qualidade dos canais de comunicação com os beneficiários do programa, } \\
\text { qualidade das mensagens, percentual do público atingindo. }\end{array}$ \\
\hline Processo de capacitação & $\begin{array}{l}\text { Avaliar os critérios de seleção utilizados para recrutar tanto os agentes de } \\
\text { implementação quantobeneficiários. }\end{array}$ \\
\hline Subsistemalogístico e operacional & $\begin{array}{l}\text { Competência dos técnicos na execução, duração e qualidade da } \\
\text { operacionalização do programa avaliação dos técnicos do governo pelos } \\
\text { agentes beneficiados. }\end{array}$ \\
\hline Processo de monitoramento e avaliação & $\begin{array}{l}\text { Financiamento e gastos, provisão de recursos matérias, suficiência dos } \\
\text { recursos qualidade da infraestrutura e material de apoio (prospecção e } \\
\text { atendimento e evolução do beneficiário). }\end{array}$ \\
\hline $\begin{array}{l}\text { Avaliar o monitoramento realizado, qual o procedimento de avaliação e os } \\
\text { métodos que contribuem para a melhoria da implementação. }\end{array}$ \\
\hline \begin{tabular}{l} 
Forado a partir de Draibe (2001). \\
\hline
\end{tabular}
\end{tabular}

A seguir serão apresentados os procedimentos metodológicos da pesquisa.

\section{METODOLOGIA}

Esta pesquisa consiste em um estudo exploratória, qualitativa e estudo de caso. No que diz respeito às pesquisas exploratórias, para Gil (2010) elas têm como principal finalidade desenvolver, esclarecer e modificar conceitos e ideias, tendo em vista a formulação de problemas mais precisos ou hipóteses pesquisáveis para estudos posteriores.

Com relação à abordagem qualitativa, Richardson (2012, p. 80), expõe que "os estudos que empregam uma metodologia qualitativa podem descrever a complexidade de determinado problema", além de analisar a interação de variáveis, compreender e classificar processos dinâmicos vividos por grupos sociais.

Nos procedimentos adotados na coleta de dados, trata-se de uma análise documental, já que utiliza de dados secundários, realizando uma entrevista junto aos professores-multiplicadores e ao Coordenador do Núcleo de Tecnologia Educacional do Município - NTE, baseada no modelo teórico de Draibe (2001), cujas dimensões consideradas foram: a) subsistema gerencial e decisório, b) processo de divulgação e informação (comunicação), c) processo de seleção, d) processo de capacitação, e) subsistema logístico e operacional, e f) processo de monitoramento e avaliação interna. Além disso, é uma pesquisa bibliográfica, fundamentando-se em fontes teóricas como livros e artigos analisando os conceitos de implementação e avaliação de políticas/programas/projetos.

0 trabalho ainda se classifica como um estudo de caso, procurando conhecer a realidade da implementação de uma política educacional, enfocando no caso: o Proinfo no Município de Mossoró/RN. 


\section{RESULTADOS E DISCUSSÕES}

Proinfo é um programa educacional criado pela Portaria n 522/MEC, de 9 de abril de 1997, para promover o uso pedagógico de Tecnologias de Informática e Comunicações (TICs) na rede pública de ensino fundamental e médio. 0 programa leva às escolas computadores, recursos digitais e conteúdos educacionais, cabendo ao Distrito Federal, Estados e Municípios a contrapartida da garantia da adequação da infraestrutura para receber os laboratórios e capacitação dos educadores para o uso efetivo das máquinas e tecnologias (BRASIL, 2007).

O Prolnfo foi oficializado pela Portaria MEC No 522, publicada em 09 de abril de 1997, instituindo 0 Programa Nacional de Informática na Educação. A Lei nº 10.172, de 9 de janeiro de 2001, cria o Plano Nacional de Educação e tratano Art. 6 da Educação a Distância e das Tecnologias Educacionais, estabelecendo suas diretrizes, traçando objetos e metas. Posteriormente, o decreto $n^{\circ} 6.094$ de 24 de abril de 2007, dispõe sobre a implementação do Plano de Metas Compromisso Todos pela Educação, pela União Federal, em regime de colaboração com municípios, Distrito Federal e Estados. Desenvolve-se mediante programas e ações de assistência técnica e financeira, com vistas à mobilização social pela melhoria da qualidade da educação básica. 0 decreto $N^{\circ} 6.300$ de 13 de dezembro de 2007, altera a portaria $N^{\circ} 522$, dispõe sobre a ampliação do Prolnfo, traça objetivos e responsabilidades para o programa, modificando o antigo Programa Nacional de Informática na Educação para Programa Nacional de Tecnologia Educacional. Sua fundamentação também é respaldada em alguns dispositivos da LDB (Lei n 9.394/96), especialmente no Art. 32, Inciso II, que objetiva para a formação básica do cidadão, no ensino fundamental, a compreensão do ambiente natural e social, do sistema político, da tecnologia, das artes e dos valores em que se fundamenta a sociedade. No Art. 35, Inciso IV, traz a compreensão dos fundamentos científico-tecnológicos dos processos produtivos, relacionando a teoria com a prática, no ensino de cada disciplina no ensino médio.

Os núcleos são estruturados com laboratórios, coordenadores e professores multiplicadores, especialistas em tecnologias de informação e comunicação. Segundo o documento "Núcleos de Tecnologia Educacional - caracterização e critérios para criação e implantação" (BRASIL, 1997b), cabem aos núcleos:

a) capacitar professores e técnicos das unidades escolares de sua área de abrangência;

b) prestar suporte pedagógico e técnico às escolas (elaboração de projetos de uso pedagógico das TIC, acompanhamento e apoio à execução, etc.);

c) realizar pesquisas e desenvolver e disseminar experiências educacionais; $\mathrm{e}$

d) interagir com as Coordenações Regionais do Prolnfo e com a Coordenação Nacional do Programa no Ministério da Educação-MEC, no sentido de garantir a homogeneidade da implementação e o sucesso do Programa (BRASIL, 1997b).

0 processo da análise das discussões aqui apresentadas sobre a avaliação de um programa governamental, no que se refere à implementação deste, estão configuradas a partir das dimensões propostas por Draibe (2001) e adaptadas na sistematização da apresentação das discussões, bem como em face de estas serem as questões maiores que nortearam a aplicação do instrumento junto aos atores pesquisados e somado as análises documentais deram suporte a construção da pesquisa avaliativa. 


\subsection{SUBSISTEMA GERENCIAL E DECISÓRIO}

De acordo com Draibe (2001), na implementação de uma política existe um sistema gerencial e decisório específico, que vai conduzir o processo. É necessário observar as características de sua estrutura organizacional e hierárquica, bem como os graus de centralização e descentralização, os mecanismos utilizados para implementar suas decisões e a natureza e os atributos do gestor.

Avaliando o subsistema gerencial e decisório do Programa Nacional de Tecnologia Educacional, o Prolnfo, apresenta em seus textos oficiais a proposta de atuar no cerne da descentralização, construindo Núcleo de Tecnologia Educacional nos estados e municípios que aderem ao programa, para promover o uso das tecnologias nas escolas.

No documento disponível pelo MEC, apresenta os Núcleos como estruturas descentralizadas de nível operacional do Prolnfo, vinculados a uma secretaria estadual ou municipal de educação e especializados em tecnologias de informação e comunicação(TIC), aplicadas à educação para garantir a parceria entre governo federal, municipal e estadual na articulação escola-tecnologia (BRASIL,1997).

A coordenadora do NTM, aqui identifica como Entrevistada 1 (E1), é quem gerencia o programa no Município de Mossoró.

O coordenador trabalha tanto a parte pedagógica - acompanhando juntamente com os professores o planejamento, observando o que está sendo trabalhado, e o que está acontecendo em sala de aula, como administrativa, tentando deixar que tudo funcione, as máquinas e a parte da infraestrutura, a agenda técnica e o acompanhamento das visitas. (ENTREVISTA, 2017)

Durante o estudo, observou-se que o modelo de descentralização enunciada pelo programa ainda está atrelado à transferência de responsabilidades e competências para os entes envolvidos. Não há um espaço de troca de informações, dificultando o trabalho dos docentes.

Há também uma grande ausência de diálogo entre o NTM e o Prolnfo, dificultando a atuação do contexto local. Foram enviadas alguns materiais sem orientações, como também, algumas distribuições por parte do Prolnfo o qual não eram repassadas para o NTM. (ENTREVISTA, 2017)

Percebe-se que a descentralização, aspecto positivo no momento da implementação do programa, não pode ser confundida como separação total entre as partes envolvidas no Prolnfo, que precisam estar em constante interação para a obtenção de melhores resultados.

\subsection{PROCESSO DE DIVULGAÇÃO E INFORMAÇÃO(COMUNICAÇÃO)}

Como explica Draibe (2001), um processo de implementação precisa de uma mínima divulgação e circulação de informações entre os que implementam as ações e aqueles que com elas se beneficiam. Precisa-se investigar, portanto, se os meios de divulgação transmitem dados de forma clara, suficiente e abrangente entre os públicos interno e externo. 


\section{ISSN - 2447-178X}

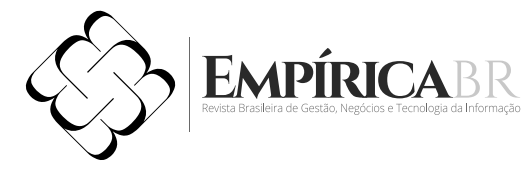

Nesta dimensão busca-se evidenciar o processo de comunicação com os beneficiários na perspectiva de atender aos objetivos institucionais do Proinfo, bem como, a diversificação dos canais de comunicação com os beneficiários do programa.

As informações do Prolnfo podem ser encontradas no site do FNDE e disponíveis para todos os interessados. Na sua seção de Apresentação são explicadas quais as intenções do programa; em Últimas Notícias tem-se uma seção com as últimas informações sobre o programa; a seção Perguntas Frequentes, contém algumas dúvidas esclarecidas; em Liberação de Recursos, acessa-se um link com informações sobre os recursos liberados por região, município e ano, conforme pesquisado; na seção Contatos, estão listados responsáveis por determinadas áreas, com e-mail; na seção Eixos de Atuação, pode-se verificar três subseção com suas apresentações, como o Projeto Um Computador por Aluno, projeto que complementou as ações do MEC referente a tecnologias na educação, distribuindo computadores portáteis aos alunos de rede pública; em Programa um Computador por Aluno, programa de registro de preço para que os estados e municípios pudessem comprar com recursos próprios, e tablets, programa também complemento o Prolnfo, com o objetivo de distribuir tablets para os professores de escolas.

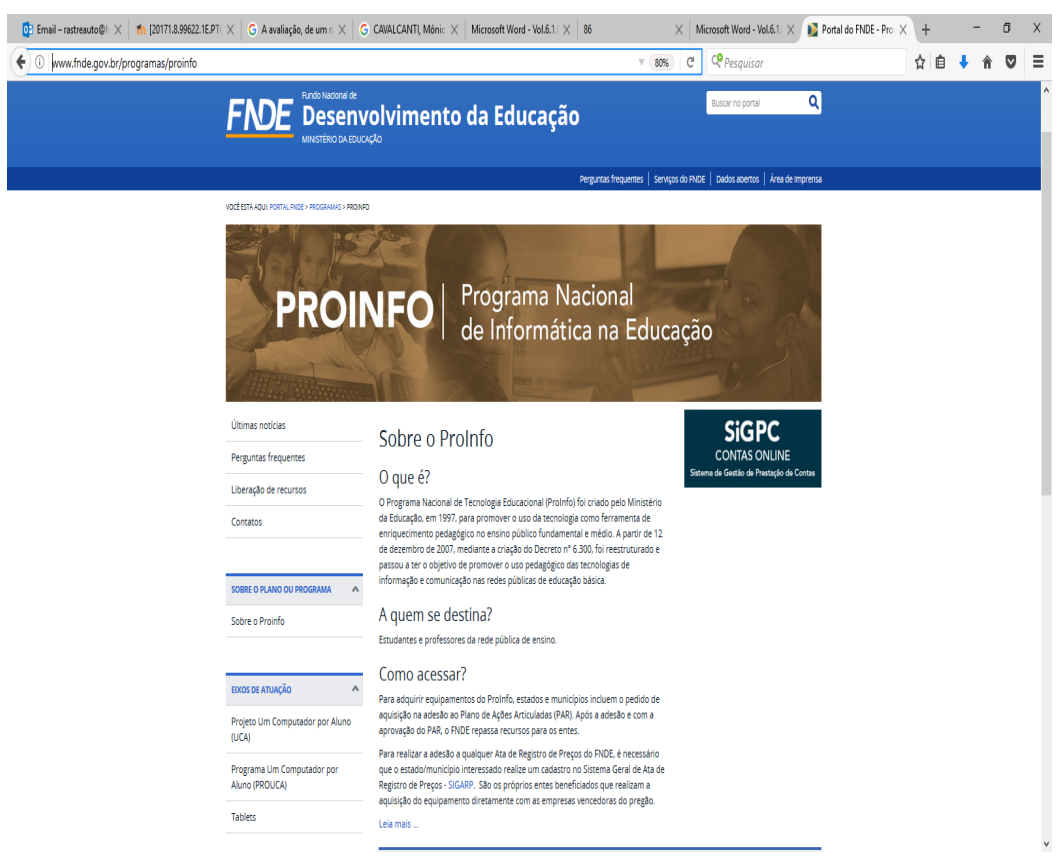

Figura 1: Página do Prolnfo.

Fonte: FNDE/Prolnfo - http://www.fnde.gov.br/programas/proinfo.

Contudo, verificou-se que algumas dessas seções não estão atualizadas, o que dificulta a pesquisa sobre mais informações do programa. Por exemplo, a seção contatos, ao clicar no link, o mesmo informa "ERRO AO ACESSAR". Possivelmente porque o programa está em declínio e sem novos investimentos. 


\section{ISSN - 2447-178X}

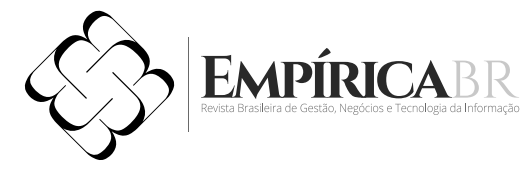

Atualmente, há uma grande dificuldade em pesquisar informações do Prolnfo, principalmente sobre os recursos e investimentos realizados. Contudo, podemos analisar alguns artigos elaborados e com o NTM, que anualmente elabora relatórios sobre o desenvolvimento do programa no município. Um dos motivos para essa dificuldade em obter informação se dá pelo motivo de que o programa está paralisada em relação ao investimento. Conforme a coordenadora do NTM, desde 2013 o programa não envia novas ferramentas -o que está ocorrendo com o programa é uma descontinuidade no aspecto da atualização e modernização dos equipamentos tecnológicos. A figura abaixo traz um print do blog do NTM.

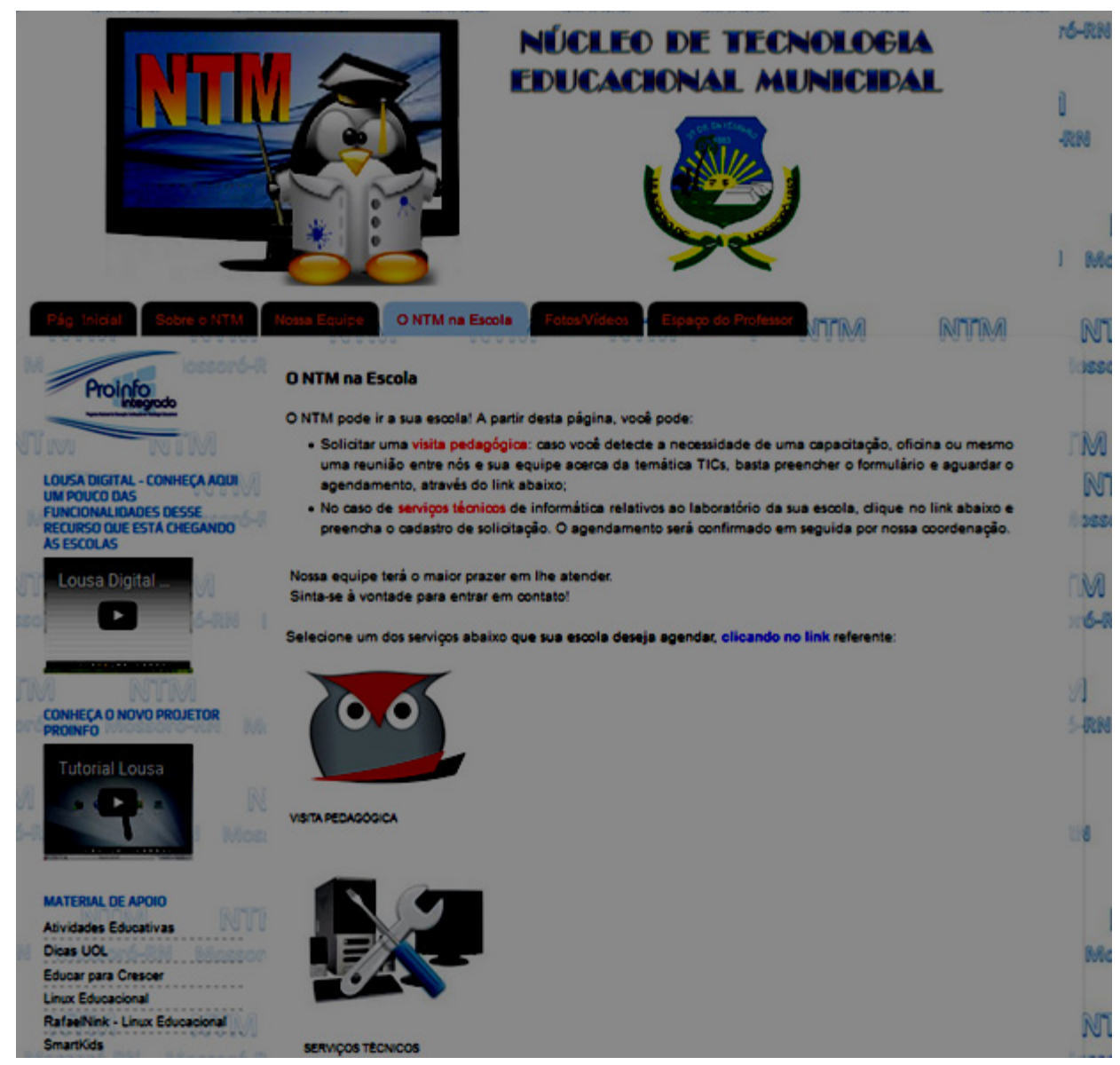

Figura 2: Blog Núcleo de Tecnologia Educacional Municipal - Link para comunicação entre escolas e núcleo.

Fonte: http://tecnologiasmossoro.blogspot.com.br/

O NTM tem um blog, atualizado pela coordenadora do Programa que contém informações sobre os cursos ofertados pelo núcleo, pois, além do apoio ás escolas que adquiriram e usam as salas de tecnologia, o NTM trabalha com cursos de capacitação. Esses cursos são ofertados por semestre e são repassadas no blog do NTM, como também no blog da prefeitura do município, e diretamente aos professores e diretores das escolas.Segundo a: 


\section{ISSN - 2447-178X}

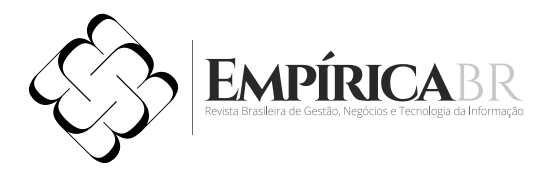

As informações também são repassadas para os professores por e-mail e enviamos comunicados aos diretores das escolas. (ENTREVISTA, 2017)

O contato das escolas para o núcleo é feita pelo blog, onde há um link para visitas técnicas, também pode ser feita por telefone do escritório do núcleo ou mesmo diretamente no escritório que fica localizado na Escola de Artes. As visitas são realizadas por ordem de contato. A comunicação direta ao programa se dá por meio dos núcleos, onde os mesmos têm e-mail, telefones e acessos no sistema.

O SIGETEC - Sistema de Gestão Tecnológico, local onde é realizado o cadastro do município para adesão ao programa há a possibilidade de realizar downloads de materiais como manual de acesso, manual de adesão, cartilhas etc. e alguns relatórios sobre a distribuição do programa em seu município ou estado. Somente o NTM tem acesso ao SIGETEC para cadastro e atualização de informação.

Em relação ao programa Prolnfo, há uma certa dificuldade em obter determinadas informações. Como citado anterior, alguns links na página do FNDE, não estão disponíveis ou não atualizados. As evidentes falhas no tocante a este processo (comunicação) comprometem o resultado final do programa.

\subsection{PROCESSO DE SELEÇÃO}

Segundo Draibe (2001) os programas envolvem algum tipo de seleção, seja de agentes que implementarão ou do público-alvo a que se dirige. Tomando como base as diretrizes de Draibe (2001) para analisar os Sistemas de Seleção de uma política ou programa, investigou-se como é feita a seleção das escolas para aderir ao programa e a seleção dos professores-multiplicadores que trabalham no NTM.

A adesão dos estados e municípios para receber os laboratórios é feita seguindo três etapas. A primeiro é a assinatura do Termo de Adesão que, segundo o MEC (BRASIL, 1997b), é o ato que representa o compromisso com os objetivos e estratégias do Programa e seus resultados, imprescindível para o recebimento dos laboratórios.

A seleção é o segundo passo no processo de adesão ao Programa pelo ente federado. Esta ação se concretiza através do cadastro do prefeito no Sistema de Gestão Tecnológica (SIGETEC), acompanhado de documentos pessoais e funcionais e da inserção das seguintes informações das escolas selecionadas: nome da escola, UF, município, código INEP e a situação da infraestrutura que irá acomodar os computadores, incluindo fotos. É uma etapa que se conclui quando todas as informações são prestadas, principalmente aquelas relativas ao local onde será instalado o laboratório que, comprovadamente, segundo o MEC (BRASIL, 2011), devendo atender os seguintes critérios como: o laboratório de informática deverá estar protegido de forma adequada contra agentes agressivos como, por exemplo, areia, poeira, chuva; a temperatura ambiente deve ser de no máximo $30^{\circ} \mathrm{C}$, os laboratórios são equipados com centrais de ar; tomadas elétricas comuns não podem ser compartilhadas com a rede elétrica dos equipamentos de informática; ausência de falhas estruturais na alvenaria do prédio; piso adequado - madeira, pedra, cimento liso, vinil, cerâmica ou equivalente; exigências mínimas da rede elétrica: fornecimento de energia elétrica de $110 \mathrm{~V}$ ou $220 \mathrm{~V}$, com capacidade de pelo menos 10KVA; quadro de distribuição de energia elétrica exclusivo para os equipamentos de informática; aterramento 


\section{ISSN - 2447-178X}

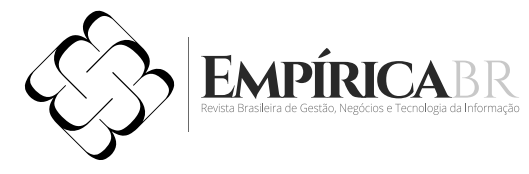

do quadro e seus circuitos (não usar o neutro da rede), com resistência menor ou igual a 10.

Quando as ferramentas eram liberadas, os técnicos só estavam autorizados a iniciarem as instalações após aprovar todos esses requisitos. Contudo, não havia nenhum monitoramento efetivo para comprovar tal feito.

Analisando os documentos do Prolnfo, verificamos que segundo o $\operatorname{MEC(1997),~em~relação~à~}$ seleção dos profissionais destinados à formação dos multiplicadores são selecionados em função de sua qualificação profissional em informática e educação. Os demais - multiplicadores e aqueles que atuarão em salas de aula - deverão ter um perfil que o leve a ser autônomo, crítico, cooperativo, comprometido, e capaz de estabelecer uma relação prazerosa com a prática de intercomunicação.

Fomos convidados em função da qualificação profissional em informática e educação. Somos funcionários do Município. (ENTREVISTA, 2017).

Estava prevista a alocação de técnicos de suporte em informática para as escolas (no mínimo um por escola). Estes técnicos, preferencialmente, seriam egressos de escolas profissionalizantes de $2^{\circ}$ grau e teriam sua formação complementada por cursos específicos, cujos currículos, também, seriam detalhados por este Programa.

\subsection{PROCESSO DE CAPACITAÇÃO}

Segundo Draibe (2001) é indispensável, em qualquer programa, verificar a capacidade dos agentes para cumprir as tarefas que lhe cabem na implementação. Nesta dimensão a discussão é norteada a partir das competências dos técnicos e dos professores-multiplicadores, coordenadores do NTM e dos professores.

A capacitação dos professores, com a finalidade de inseri-los nesse novo ambiente de tecnologias na escola, acontece por meio do Programa Nacional de Formação Continuada em Tecnologia Educacional (Prolnfo Integrado), objetivando a formação continuada dos educadores para uso das tecnologias. A formação contempla uma carga horária de $580 \mathrm{~h} / \mathrm{a}$, distribuídas e oferecidos através de quatro cursos que acontecem no espaço do NTM:

- Introdução à Educação Digital-60h; Este curso tem o objetivo de contribuir para a inclusão digital de profissionais da educação e prepará-los para utilizarem os recursos e serviços dos computadores nas escolas.

- Tecnologias na Educação: ensinando e aprendendo com as TIC (60h) - visa oferecer subsídios teórico-metodológicos práticos para que os professores e gestores escolares possam refletir sobre o potencial das TIC no ensino-aprendizagem da escola.

- Elaboração de Projetos; Visa capacitar professores e gestores escolares para que eles possam desenvolver projetos que integram as tecnologias.

- Redes de aprendizagem; objetiva fortalecer no docente a compreensão do papel da escola frente à cultura digital.

Ao final de cada curso, o NTM realiza uma avaliação com os professores para monitorar seu desenvolvimento no curso. 


\section{ISSN - 2447-178X}

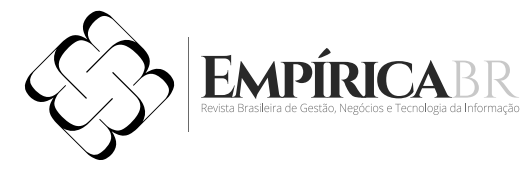

O processo de capacitação de recursos humanos, professores-multiplicadores e técnicos em informática, para o Programa, segundo MEC (1997) é desenvolvido da seguinte forma: a) seleção e capacitação de professores oriundos de instituições de ensino superior técnico-profissionalizante, destinados a ministrar a formação dos professores multiplicadores; $b$ ) seleção e formação de professores multiplicadores, oriundos da rede pública de ensino de $1^{\circ}$ e $2^{\circ}$ graus e de instituições de ensino superior e técnico-profissionalizante; c) seleção e formação de técnicos de suporte em informática e telecomunicações; d) seleção e formação de professores da rede pública de ensino de $1^{\circ}$ e $2^{\circ}$ graus (que atuarão nas escolas, com os equipamentos e software fornecidos pelo MEC).

Nas entrevistas observou-se que não houve capacitação adequada aos professores, como afirmou a Professora-multiplicadora do NTM:

Somente foram oferecidos pelo Programa os três cursos (Introdução a Educação Digital, Ensinando e Aprendendo com as Tecnologias e Elaboração de Projetos. Esses cursos dão suporte para você conhecer o material e para você trabalhar com a formação continuada dos professores. Mas eles não formam os professores/ multiplicadores para estar no Núcleo, nós temos que ir atrás. (ENTREVISTA, 2017).

Conforme documento de criação dos NTE (BRASIL,1997), também consiste em realizar capacitação básica ou complementar para os multiplicadores/formadores do Núcleo. Contudo, podemos observar pelo discurso da professora-multiplicadora que, o programa deixa uma lacuna na formação dos multiplicadores/formadores que se encerra nos cursos que são orientados para a execução no NTM. Isso acontece também com o técnico responsável pela manutenção dos equipamentos, o mesmo não tem nenhum curso ou reciclagem ofertado pelo programa.

\subsection{SISTEMA LOGÍSTICO E OPERACIONAL}

Neste tópico, busca-se compreender como a política é financiada e operacionalizada pelos gestores para que as ações de implementação se desenvolvam de acordo com os parâmetros planejados. Aspectos como suficiência de recursos financeiros, bem como os prazos de chegada desses recursos ao órgão gerenciador, são fundamentais para o bom funcionamento dos processos envolvidos. Além disso, no que diz respeito a recursos materiais, muitas vezes a base material específica na qual a política se apoia, como explica Draibe (2001), é crucial para o seu êxito.

No documento de Diretrizes do Prolnfo (1997) estava previsto o investimento orçado para a implantação do Programa foi de $\mathrm{R} \$ 476$ milhões de reais para capacitação e suporte, aquisição de equipamentos, adaptação das instalações físicas dos NTE (redes locais) e custeio das equipes. A previsão era que esses recursos seriam próprios e de financiamentos externos, através do Banco Interamericano de Desenvolvimento - BID. O orçamento citado refere-se apenas à contrapartida do governo federal, não estando incluídos nestes os recursos aplicados no Programa pelos governos estaduais e municipais. 


\section{ISSN - 2447-178X}

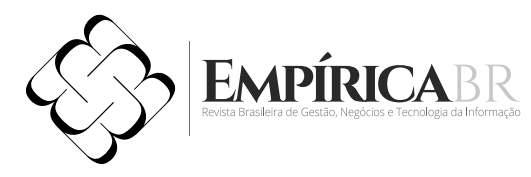

A provisão de recursos materiais é feita pelo governo federal, o Fundo de Desenvolvimento da Educação (FNDE) facilita a aquisição desses equipamentos com recursos dos próprios estados e municípios por meio da adesão ao pregão eletrônico disponível no sítio eletrônico:www.fnde.gov.br/ sigarpweb.

Em relação aos recursos para o NTM há uma ausência de recursos financeiros tanto para sua efetivação no espaço próprio, quanto para investimento nos próprios materiais que poderiam ser adotados no Núcleo, tanto em nível de município quanto de governo federal. Os núcleos não recebem recursos financeiros. A prefeitura repassa materiais de escritório, como papeis, canetas e as pessoas que trabalham no núcleo são funcionários da prefeitura. Como afirmou Socorro Souza, professoramultiplicadora do NTM.

\footnotetext{
O Federal envia as ferramentas e os municípios e estados disponibilizam os servidores para trabalharem nos núcleos. E as escolas disponibilizam a infraestrutura. Os recursos provirão do MEC (recursos próprios e financiamentos externos), estados e municípios. O Federal envia as ferramentas e os municípios e Estados disponibilizam os servidores para trabalharem nos núcleos. E as escolas disponibilizam a infraestrutura. (ENTREVISTA, 2017)
}

No momento, o projeto está sem investimento. Apesar do Proinfo ter sido afetado, pelo fato de estar em fase de paralisação em razão de cortes de financiamento sofridos no campo de educação, o núcleo tem mantido sua função, buscando continuidade ao que foi orientado a fazer desde o início de sua implantação e ainda cria nova possibilidades de cursos, não se restringindo apenas ao projetado pelo programa.

\subsection{PROCESSO DE MONITORAMENTO E AVALIAÇÃO}

Como menciona Draibe (2001), a implementação de políticas tende a ser monitorada pelos seus gestores, mesmo que de forma implícita. É necessário saber se as avaliações internas se constituem como um procedimento regular, se o conteúdo e os métodos contribuíram efetivamente para a implementação da política, inclusive provocando correções no processo, e se os sujeitos têm acesso a resultados sistematizados de avaliações, sejam internas ou externas.

No plano inicial do Prolnfo, foi previsto que o Programa deveria ser submetido a um processo de acompanhamento e avaliação, por duas razões principais: primeiro, em função do vulto dos investimentos programados, e segundo, pela complexidade inerente a um processo de introdução de tecnologia de ponta em sistemas tradicionais de ensino. O Prolnfo previu um mecanismo de acompanhamento e avaliação no sentido de mensurar os resultados físicos do programa (como também) o impacto da tecnologia no processo educacional e as melhorias na qualidade, eficiência e equidade do ensino de $1^{\circ}$ e $2^{\circ}$ graus. Esse mecanismo seria desenvolvido pelo MEC e também definido nos projetos estaduais e das escolas em função dos objetivos e metas definidas pelo programa, uma vez que previa. Tendo como base um processo de acompanhamento e avaliação, com definição de indicadores de desempenho 
que permitam medir, além dos resultados físicos do Programa, o impacto da tecnologia no processo educacional e as melhorias na qualidade, eficiência e equidade do ensino de $1^{\circ}$ e $2^{\circ}$ graus:

- · índices de repetência e evasão;

- habilidades de leitura e escrita;

- ·compreensão de conceitos abstratos;

- ·facilidade na solução de problemas;

- ·utilização intensiva de informação em várias fontes;

- desenvolvimento das habilidades de trabalho em equipe;

- ·implementação de educação personalizada;

- - acesso à tecnologia por alunos de classes socioeconômicas menos favorecidas;

- ·desenvolvimento profissional e valorização do professor.

Em relação ao acompanhamento e avaliação do Programa, o Ministério solicitava aos Estados, até 2002, o envio de relatórios anuais sobre as ações realizadas, como também a atualização sistemática dos dados através de sistema eletrônico -SIP -Sistema de Informações do Prolnfo, hoje SIGETEC. Este sistema permite que os estados e MEC tenham uma radiografia do parque tecnológico instalado e o desenvolvimento das diversas ações pelos NTE, por período, região, atividades. Os multiplicadores lotados nos NTE são os responsáveis por alimentar o sistema com as informações, cujos dados podem ser utilizados pelas secretarias de educação, coordenações estaduais do Programa e pelo MEC, para reformulação de políticas. Infelizmente, muitos NTE não mantêm os dados atualizados e não há a certeza de que os mesmos utilizam os relatórios gerados pelo sistema para avaliação das ações desenvolvidas, bem como sua reformulação.

Em relação ao acompanhamento e avaliação do Programa, o Ministério solicitava aos Estados, até 2002, o envio de relatórios anuais sobre as ações realizadas, como também a atualização sistemática dos dados através de sistema eletrônico - SIP - Sistema de Informações do Prolnfo, hoje SIGETEC. Este sistema permite que os estados e MEC tenham uma radiografia do parque tecnológico instalado e o desenvolvimento das diversas ações pelos NTE, por período, região, atividades. Os multiplicadores lotados nos NTE são os responsáveis por alimentar o sistema com as informações, cujos dados podem ser utilizados pelas secretarias de educação, coordenações estaduais do Programa e pelo MEC, para reformulação de políticas.

Infelizmente, muitos NTE não mantêm os dados atualizados e não há a certeza de que os mesmos utilizam os relatórios gerados pelo sistema para avaliação das ações desenvolvidas, bem como sua reformulação.

\section{CONSIDERAÇÕES FINAIS}

Esta pesquisa objetivou avaliar a implementação do Programa Nacional de Tecnologia Educacional a partir do modelo conceitual desenhado no percurso metodológico, assim fazendo as considerações finais.

Em relação ao Sistema Gerencial e Decisório do programa, verificou-se que o programa se intitula como ser descentralizador, mas a dinâmica de organização aponta para um deslocamento de 
competência. Ou seja, a União, envia os equipamentos e os entes federados (municípios e estados) disponibilizam a infraestrutura exigida. Contudo, é possível verificar que o município não tem recurso suficientes para fazer a reposição dos materiais (manutenção dos equipamentos). Nesse sentido, a descentralização presente nas intenções desse Programa é somente para que as instâncias locais assumam a reponsabilidade, já que a elas não são destinados recursos financeiros para o funcionamento do programa.

No que diz respeito aos Processo de Divulgação e Informação, o fato do órgão possuir ferramentas e sistemas ligados a TI não significa que consiga estabelecer uma comunicação eficaz entre os sujeitos. Observamos que, muitas vezes o programa enviou novos equipamentos para as escolas nas quais o próprio núcleo não tinha acesso, lembrando que o núcleo é responsável pelos relatórios e capacitação aos professores para manusear as TI. Havendo uma grande falha na comunicação entre os profissionais e o programa, criando uma quebra no objetivo do programa.

Com relação ao sistema de Seleção, é constituída por critérios pré-estabelecidos, contudo não é uma seleção rigorosa. Em relação a seleção das escolas, não há como realizar uma verificação das informações dos laboratórios das escolas, para liberação dos equipamentos, ficando na responsabilidade do técnico e sua palavra.

Com relação ao sistema de Capacitação, nenhum dos sujeitos envolvidos na implementação da política deve ser privado da prerrogativa de capacitação oferecida pelo órgão. Um Programa que não capacita seus funcionários gera lacunas que possivelmente irão se transformar em falhas de execução da política, as quais exigirão uma reprogramação em algum aspecto.

No que tange o sistema Logístico e Operacional, há uma descontinuidade no programa pelo governo federal. Novos investimentos para o programa foram cortadas, comprometendo o planejamento de ações. Com as máquinas desatualizadas, configurações ultrapassadas, lentas ou até mesmo danificadas sem peças no mercado para reposição. Essa é uma realidade que se agrava nas escolas da rede municipal. Está se falando de equipamentos que foram adquiridos em 2008 a 2010, com pregão 2007 ou seja, máquinas com 8 anos de uso e ou fabricação, modelos ultrapassados que não se encontra mais compatível com os atuais sistemas operacionais

Em se tratando do Sistema de Monitoramento e Avaliação, todos os sujeitos envolvidos na política necessitam de avaliações internas para contribuir com melhorias no processo de implementação da política. Por exercerem diariamente atividades, e necessário avaliar e serem avaliados para colaborar com a melhoria das ações. A elaboração de instrumentos pautadas em critério científicos torna esses procedimentos mais regulares e formaliza o registro dos resultados. No entanto, abre-se uma lacuna entre sujeitos envolvidos caso não haja a sistematização e a socialização desses resultados.

\section{REFERÊNCIAS}

1. ALA-HARJA, M.; HELGASON, S. Em direção às melhores práticas de avaliação. Revista do Serviço Público, v. 51, n. 4, p. 5-60, 2000. 


\section{ISSN - 2447-178X}

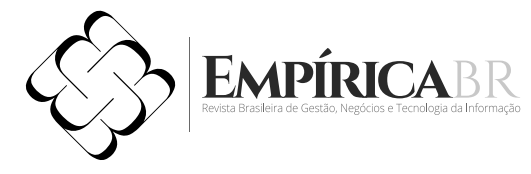

2. ALMEIDA, M. E. ProInfo: Informática e Formação de Professores. Brasília: MEC/ Secretaria de Educação à Distância, 2000.

3. BEHAR, P. A. Modelos Pedagógicos em Educação a distância. Porto Alegre Ed: Artmed, 2009.

4. BRASIL. Constituição Federal do Brasil. Brasília, 1988

5. ___ Plano Nacional de Educação. Brasília: Câmara dos Deputados, Coordenação de Publicações, 2002.

6. Programa de Informática na Educação. Ministério da Educação. Prolnfo: Diretrizes. Documento, 1997.

7. Prolnfo: Perspectivas e desafios: Relatóriode Avaliação -UnB. Ministério da Educação.. Brasília. Documento, 2002.

8. BRASIL. Presidência da República. Casa Civil. Subchefia para Assuntos Jurídicos. Decreto no 6.300, de 12 de dezembro de 2007. Dispõe sobre o Programa Nacional de Tecnologia Educacional - Prolnfo. Disponível em: <http://www.planalto.gov.br/ccivil_03/_Ato2007-2010/2007/Decreto/D6300. htm>. Acesso em: 20 maio 2017.

9. Diretrizes do Programa Nacional de Informática da Educação (Prolnfo). Secretaria de Educação á Distancia. Ministério da Educação.. Brasília: julho de 1997.

10. Presidência da República. Casa Civil. Subchefia para Assuntos Jurídicos. Decreto nº 6.300, de 12 de dezembro de 2007. Dispõe sobre o Programa Nacional de Tecnologia Educacional - Prolnfo. Disponível em: <http://www.planalto.gov.br/ccivil_03/_Ato2007-2010/2007/Decreto/D6300. htm>. Acesso em: 25 set. 2011

11. Presidência da República. Casa Civil. Subchefia para Assuntos Jurídicos. Decreto ${ }^{\circ}$ 6.300, de 12 de dezembro de 2007. Dispõe sobre o Programa Nacional de Tecnologia Educacional -

12. CAVALCANTI, M. M. A. Avaliação de políticas públicas e programas governamentais: uma abordagem conceitual. Disponível em: http://www.socialiris.org/antigo/imagem/boletim/ arq48975df171def.pdf . Acessado em 25 de maio de 2017.

13. COTTA, T. C. Metodologia de avaliação de programas sociais: análise de resultados e de impactos. Revista do Serviço Público, Brasília, v. 49, n. 2. p. 105-126, abr./jun. 1998. 


\section{ISSN - 2447-178X}

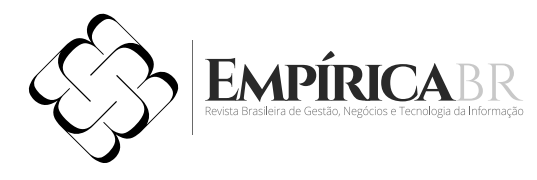

14. DEMO, P. Educação Hoje: "Novas" tecnologias, pressões e oportunidades. São Paulo: Atlas, 2009. 15. DRAIBE, S. M. Avaliação de implementação: esboço de uma metodologia de trabalho em políticas públicas. In: BARREIRA, M. C. R. N; CARVALHO, M. do C. B. de. (Orgs.).Tendências e perspectivas na avaliação de políticas e programas sociais. São Paulo: IEE/PUC/SP, 2001

16. GIL, A. C. Como elaborar projetos de pesquisa. 5. ed. São Paulo: Atlas, 2010.

17. GRISNSPUN, M. P. S. Zippin (Org.). Educação tecnológica: desafios e perspectivas. São Paulo: Cortez, 1999.

18. FAVA, R. Educação 3.0. São Paulo: Saraiva, 2014.

19. MORAN, J. M. Novas tecnologias e o re-encantamento do mundo. Revista Tecnologia Educacional. Rio de Janeiro, vol. 23, n.126, p 6., setembro-outubro, 1995.

20. LÉVY, P. O que é o virtual? São Paulo: Ed. 34, 1996.

21. MARJUKKA, A.; HELGASON, S. Em direção às melhores práticas de avaliação. Brasília-DF: Revista do Serviço Público, Brasília, ano 51, número 4, out-dez. 2000.

22. MORAES, M. C. O paradigma educacional emergente. Campinas: Papirus, 1998.

23. MORAN, J. M. Novas tecnologias e mediação pedagógica. São Paulo: Papirus, 2000.

24. RAMOS, M. P.; SCHABBACH, L. M. O estado da arte da avaliação de políticas públicas: conceituação e exemplos de avaliação no Brasil. Revista de Administração Pública, Rio de Janeiro, v. 46, n. 5, p. 1271-1294, 2012.

25. RICHARDSON, R.J. Pesquisa social: métodos e técnicas. 3. ed. São Paulo: Atlas, 2012.

26. RUA, M. G. Políticas Públicas: especialização em Gestão Pública Municipal. Brasília: CAPES/UAB, 2009.

27. SANDHOLTZ, J.; RINGSTAFF, C.; DWYER, D. Ensinando com Tecnologia: Criando Salas de Aula Centradas nos Alunos. Porto Alegre : Artes Médicas, 1997.

28. SILVA, P. L. B.; MELO, M. A. B. O processo de implementação de políticas públicas no Brasil: características e determinantes da avaliação de programas e projetos. NEEP-UNICAMP, Caderno n 48, 2000. 


\section{ISSN - 2447-178X}

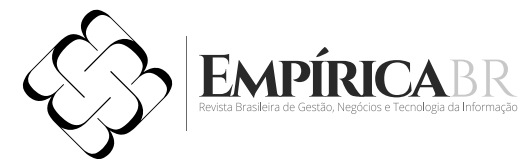

29. STEPHANOU, M. C. Análise comparativa das metodologias de avaliação das agências de fomento internacionais BID e BIRD em financiamentos de projetos sociais no Brasil. Civitas, Porto Alegre, v. 5, n.1, jan.-jun. 2005

30. THOENIG, J. C. A avaliação como conhecimento utilizável para reformas de gestão pública. Revista do Serviço Público, Brasília, v. 51, n. 2, p. 54-70, abr./jun. 2000. 